\title{
The 6-Min Walk Test in Pulmonary Arterial Hypertension: Only for Bad News?
}

\author{
Gaël Deboeck \\ Department of Cardiology, Erasme University Hospital Brussels, Brussels, Belgium
}

In the present issue of Respiration, Huang et al. [1] show that an early decline in the 6-min walk distance predicts clinical worsening in pulmonary arterial hypertension $(\mathrm{PAH})$. The 6-min walk distance was measured at the time of diagnosis and after 6 months of the initiation of $\mathrm{PAH}$-targeted therapies in a population of 100 idiopathic $\mathrm{PAH}$ patients. Both the 6-min walk distance at baseline and its decline by more than $35 \mathrm{~m}$ after 6 months were predictive of clinical worsening defined by clinical features of right heart failure, admission to hospital for $\mathrm{PAH}-$ related respiratory or cardiac causes, initiation of intravenous prostanoids after failing oral therapy, and lung transplantation or death [1]. The fact that the 6-min walk distance predicts survival in pulmonary hypertension is no new finding, but it has been subject to controversy in recent years, though probably wrongly so [2].

The 6-min walk test is a test of aerobic exercise capacity which is based on the linear relationship between maximum oxygen consumption $\left(\mathrm{VO}_{2} \mathrm{max}\right)$ and maximal averaged speed of running/walking in healthy subjects [3] or heart failure patients [4]. The correlation may not be very tight because of differences between the subjects' walking skills, mechanical efficiency or neuromuscular coordination [2]. Because $\mathrm{VO}_{2}$ is linearly related to cardiac output, the 6-min walk distance may be considered as an indirect measure of the ability of the heart to in- crease cardiac output (i.e. the cardiac reserve) $[2,5]$. The 6-min walk distance has been repeatedly shown to be one of the strongest independent predictors of outcome in $\mathrm{PAH}$, at initial evaluation as well as during follow-up after the institution of targeted therapies [6, 7]. Meta-analyses of randomized controlled trials which reported a significant improvement in the 6-min walk distance achieved by 3-4 months of targeted therapies showed that this was associated with an almost 50\% decrease in mortality [8]. Hence the simple concept that a better 6-min walk test reflects less severe disease. So, what is the controversy about?

Systematic meta-analyses on the effect of PAH-specific therapies have shown that changes in the 6-min walk distance from baseline are not related to outcome [8-10]. A recent monocentric study also showed no relation between prognosis and change in the 6-min walk distance after initiation of PAH-targeted therapy [11]. In another meta-analysis on 10 trials which had recruited 2,404 patients, placebo-corrected change in the 6-min walk distance was related to clinical outcome but only explained $22 \%$ of the drug effect [12]. These reports casted doubt on the ability of the 6-min walk test to assess response to treatment and to be a reliable index of disease progression in pulmonary hypertension.

\section{KARGER 125}

C 2015 S. Karger AG, Base

0025-7931/15/0895-0363\$39.50/0

E-Mail karger@karger.com

www.karger.com/res
Gaël Deboeck

Department of Cardiology, Erasme University Hospital Brussels Route de Lennik 808 BE-1070 Brussels (Belgium)

E-Mail Gael.Deboeck@erasme.ulb.ac.be 
Why is the absolute 6-min walk distance measured at baseline and after specific PAH therapies predictive of outcome, whereas change following these treatments is not? Targeted therapies stabilize rather than reverse the course of the disease [8]. Changes under treatment are small in regard to the absolute distance walked. Consider a randomized controlled trial of an intervention associated with a significant increase in the 6-min walk distance from $360 \pm 40$ to $400 \pm 40 \mathrm{~m}$. The change, here, is hardly over the threshold of 30-40 m associated with better clinical condition in PAH. With a standard deviation of the magnitude of the increase, the effect may be not significant because the signal would be too feeble in regard to background noise. This may be the reason why metaanalyses of randomized controlled trials of targeted therapies in PAH also could not find any relevance in the change in cardiac output, pulmonary vascular resistance or right atrial pressure, which are also robust predictors of outcome in $\mathrm{PAH}$ patients at initial evaluation or during follow-up [13].
$\mathrm{PAH}$ is an aggressive disease of rapid evolution. Huang et al. [1] show, as Farber et al. [14] already did in a recent study derived from the US Registry to Evaluate Early and Long-Term Pulmonary Arterial Hypertension Disease Management (REVEAL), that the decrease, not the increase, in the 6-min walk distance is associated with survival. Prognosis under treatment stays poor in $\mathrm{PAH}$ with rapid degradation of patients undergoing progression of the disease. Accordingly, the magnitude of negative changes is proportionally greater, and so are the signal to noise ratio and the likelihood of $\mathrm{p}<0.05$ levels of significance.

Huang et al. [1] are to be commended for their elegant study which rehabilitates the 6-min walk test as clinically meaningful in the initial evaluation and also follow-up of PAH patients. Like any other clinical test, it has limitations and must be integrated in a clinical context. The 6-min walk test is not only for bad news.

\section{References}

$>1$ Huang J, Mehta S, Mura M: Early decline in six-minute walk distance from the time of diagnosis predicts clinical worsening in pulmonary arterial hypertension. Respiration 2015; 89:365-373.

-2 Naeije R: The 6-min walk distance in pulmonary arterial hypertension: 'Je t'aime, moi non plus'. Chest 2010;137:1258-1260.

$>3$ Cooper KH: A means of assessing maximal oxygen intake. Correlation between field and treadmill testing. JAMA 1968;2033:201-204.

4 Deboeck G, Niset G, Lamotte M, Vachiéry JL, Naeije R: Exercise testing in pulmonary arterial hypertension and in chronic heart failure. Eur Respir J 2004;23:747-751.

$\checkmark 5$ Deboeck G, Taboada D, Hagan G, Treacy C, Page K, Sheares K, Naeije R, Pepke-Zaba J: Maximal cardiac output determines $6 \mathrm{~min}$ utes walking distance in pulmonary hypertension. PLoS One 2014;9:e92324.
-6 Deboeck G, Scoditti C, Huez S, et al: Exercise to predict outcome in idiopathic vs. associated pulmonary arterial hypertension. Eur Respir J 2012;40:1410-1419.

7 Sitbon O, Humbert M, Nunes H, et al: Longterm intravenous epoprostenol infusion in primary pulmonary hypertension: prognostic factors and survival. J Am Coll Cardiol 2002; 40:780-788.

8 Galiè N, Manes A, Negro L, Palazzini M, Bacchi-Reggiani ML, Branzi A: A meta-analysis of randomized controlled trials in pulmonary arterial hypertension. Eur Heart J 2009;30: 394-403.

$>9$ Savarese G, Paolilo S, Costanzo C, et al: Do changes of 6-min walk distance predict clinical events in patients with pulmonary arterial hypertension? A meta-analysis of 22 randomized trials. J Am Coll Cardiol 2012;60:11921201.
10 Macchia A, Marchioli R, Tognoni G, Scarano M, Marfisi R, Tavazzi L, Rich S: Systematic review of trials using vasodilators in pulmonary arterial hypertension: why a new approach is needed. Am Heart J 2010;159:245257

11 Nickel H, Golpon H, Greer M, et al: The prognostic impact of follow-up assessments in patients with idiopathic pulmonary arterial hypertension. Eur Respir J 2012;39:589-596.

12 Gabler NB, French B, Strom BL, et al: Validation of 6-min walk distance as surrogate end point in pulmonary arterial hypertension. Circulation 2012;126:349-356.

13 Savarese G, Musella F, D’Amore C, et al: Haemodynamics, exercise capacity and clinical events in pulmonary arterial hypertension. Eur Respir J 2013;42:414-424.

14 Farber HW, Miller DP, McGoon MD, Frost AE, Benton WW, Benza RL: Predicting outcomes in pulmonary arterial hypertension based on the 6-minute walk distance. J Heart Lung Transplant 2014, Epub ahead of print. 